\title{
Working Memory and Exploration in Training the Knowledge and Skills Required by Digital Systems
}

\author{
Jean L. Dyer \\ U.S. Army Research Institute \\ Robin S. Salter \\ Aubum University \\ Consortium Research Fellows Program
}

\author{
Infantry Forces Research Unit \\ Scott E. Graham, Chief
}
U.S. Army Research Institute for the Behavioral and Social Sciences 5001 Eisenhower Avenue, Alexandria, Virginia 22333-5600

December 2001

Army Project Number 20262785A790
Personnel Performance and

Training Technology

Approved for public release; distribution is unlimited. 